Check for updates

Cite this: RSC Adv., 2017, 7, 51151

Received 29th September 2017 Accepted 22nd October 2017

DOI: $10.1039 / c 7 r a 10767 f$

rsc.li/rsc-advances

\section{Comparative evaluations on phenolic antioxidants of nine adulterants and anti-inflammation of four alternatives with their original herb Erycibe schmidtii $\uparrow$}

\begin{abstract}
Qiang Xue, Hang Fan, Ke Li, Lingguang Yang, Liwei Sun* and Yujun Liu (DD*
Erycibe schmidtii is widely used as folk medicine in China for treatments of various inflammations. Recently, with reduction of its wild sources, various adulterants have been misused as substitutes. To distinguish reliable alternatives from various adulterants, total phenolics and antioxidant activities of E. schmidtii and its nine adulterants, as well as three marker compounds of E. schmidtii defined by Chinese Pharmacopoeia were simultaneously quantified. And HPLC fingerprints of these ten herbs were established. Compared with E. schmidtii (S1), Porana sinensis (S2), Porana sinensis var. delavayi (S3), Celastrus hindsii (S4), and Morinda umbellata (S5) exhibited similar or higher total phenols, flavonoids and tannins along with similar or greater capacities scavenging $\mathrm{DPPH}^{\bullet}, \mathrm{ABTS}^{+}$and $\mathrm{AAPH}^{\bullet}$, contained similar or higher total amounts of the three marker compounds, and possessed higher similarities in HPLC profiles. The other five adulterants (S6-S10, i.e., Illigera parviflora, Morinda parvifolia, Piper puberulum, Piper kadsura and lodes seguini in sequence) were identified as absolute fakes, thus were excluded from alternatives of S1. Further anti-inflammatory experiments with LPS-induced RAW264.7 macrophages cells on NO release and transcriptions of inflammatory factors iNOS, COX-2, IL- 6 and IL-1 $1 \beta$ showed that S2 and S3 possessed higher anti-inflammation activities than and similar mechanisms to those of S1. Taken together, S2 and S3 could be the best potentially alternatives of E. schmidtii among the nine adulterants. S4 and S5 might be also considered as alternatives for they contained similar fundamental compounds and equally impressive anti-inflammatory potential with E. schmidtii concerning iNOS and coX-2.
\end{abstract}

\section{Introduction}

Erycibe schmidtii Craib (Convolvulaceae) is a traditional Chinese herb, which is mainly distributed in Southeast Asia and Australia. In China, it is found in Southern provinces such as Guangdong and Guangxi, and its roots and stems are widely used as folk medicines for treatments of various inflammations. Recently, with reduction of wild E. schmidtii sources, ${ }^{\mathbf{1}}$ at least nine adulterants as listed below in Materials and methods have emerged in herbal markets. However, few studies have carried out on comparison of E. schmidtii with its adulterants. Therefore, comparing and finding out its potentially effective alternatives are of great significance as well as urgent.

Phenolics, a large group of plant secondary metabolites, including simple phenols, flavonoids, anthocyanins and

National Engineering Laboratory for Tree Breeding, College of Biological Sciences and Biotechnology, Beijing Forestry University, Beijing 100083, China. E-mail: xuetian20130607@163.com;_fwqh1990@163.com; like17931@163.com; yanglingguangxdjqz@163.com; lsun2013@bjfu.edu.cn; yjliubio@bjfu.edu.cn

$\uparrow$ Electronic supplementary information (ESI) available. See DOI: 10.1039/c7ra10767f tannins, have attracted more and more attention in recent years due to their antioxidant, antimicrobial, anticancer, antifungal, and anti-inflammatory activities. ${ }^{2-6}$ Previous phytochemical investigations revealed that main constituents of $E$. schmidtii are coumarins, chlorogenic acid derivatives, and flavonoids. ${ }^{7-9}$ Among them, chlorogenic acid and two coumarins, i.e., scopoletin and scopolin, are chemical markers that are determined as standards by the Chinese Pharmacopoeia for discriminating E. schmidtii from its various adulterants.

Moderate oxidative stress is necessary for aerobic life. However, under certain conditions, it can also be toxic thus must be responsible for causing a variety of diseases, including arthritis, cancer, cardiovascular diseases, cataracts, atherosclerosis, diabetes, immune deficiency diseases and ageing. ${ }^{\mathbf{1 0 - 1 5}}$ Antioxidants such as various phenolics exhibit abilities of scavenging free radicals produced by oxidative stresses and might be important tools for prevention or postponement of these diseases. Hsu et al. ${ }^{16}$ reported that E. schmidtii possess considerable antioxidant capacities, indicating that antioxidant activity might also be employed for discriminating $E$. schmidtii from its adulterants. Recently, there are various methods 
available for evaluating antioxidant capacities based on different principles and mechanisms of action. Among these methods, DPPH, ABTS and ORAC assays are used widely, ${ }^{17,18}$ in which the former two are based on electron transfer reaction and the latter follows the principle of hydrogen atom transfer.

Chromatographic fingerprinting can be obtained with various analytical techniques, such as GC, HPLC, high performance thin layer chromatography, and capillary electrophoresis, ${ }^{19}$ and it has also been applied to screen herbs such as adulterated and authentic commodities of Pericarpium Citri Reticulatae and Pericarpium Citri Reticulatae Viride, ${ }^{20}$ plant origins of Ganoderma lucidum, ${ }^{21,22}$ as well as cultivation areas of Angelica acutiloba. ${ }^{23}$ In addition, several chemometric methods applied to fingerprinting such as similarity evaluation, hierarchical clustering analysis and principal component analysis make it easier to get more comprehensive and intuitive information.

To achieve potentially effective alternatives to $E$. schmidtii, it is the most important to compare their anti-inflammatory activities. Inflammation, a fundamental and complex biological process in response to tissue injuries and infections, is indispensable for homeostasis, thus is finely regulated. Inflammation plays a vital role in pathological processes of several diseases such as arthritis, ${ }^{24}$ diabetes, ${ }^{25}$ Alzheimer's disease $^{26}$ and cancer. ${ }^{27}$ As the first line providing defence against invaders, macrophages can protect host from damaging triggered by inflammatory inducing factors such as lipopolysaccharides (LPS) and secrete pro-inflammatory cytokines and mediators such as NO, prostaglandin E2 (PGE2), interleukin-6 (IL-6) and interleukin-1 $\beta$ (IL-1 $\beta)^{28}$ which are regarded as important inducers and enhancers in the development of inflammation. Hence, LPS-induced macrophages are the most frequently used cellular model to assess the activities of antiinflammatory drugs in vitro.

In the present study, total phenolic components and antioxidant activities of $E$. schmidtii and its nine adulterants, as well as the three marker compounds of E. schmidtii were simultaneously quantified. A concise and efficient HPLC fingerprint for each of these ten vine herbs was also developed. On this basis, anti-inflammatory activities of $E$. schmidtii and its four alternatives were further evaluated, their mechanisms were deliberated, and Porana sinensis and P. sinensis. var. delavayi were finally determined as two of the best potentially effective alternatives to $E$. schmidtii. To our knowledge, this is the first report to comprehensively analyze and compare E. schmidtii of so many indexes with its nine adulterants.

\section{Materials and methods}

\subsection{Chemicals and preparation of herb extracts}

Methanol and formic acid of chromatographic grade were purchased from Thermo Fisher Scientific Inc. (Tedia, USA). Standard chlorogenic acid, scopoletin, scopolin, gallic acid and rutin were bought from National Institutes for Food and Drug Control (Beijing, China). 1,1-Diphenyl-2-picrylhydrazyl (DPPH), 2,2'-azinobis-(3-ethylbenzthiazoline-6-sulphonate) (ABTS), 6hydroxy-2,5,7,8-tetramethyl-chroman-2-carboxylic acid (trolox), Folin-Ciocalteu reagent, 2,2'-azobis(2-methylpropionamidine) dihydrochloride (AAPH), lipopolysaccharide (LPS) from Escherichia coli (0111:B4), Griess reagent and dimethyl sulfoxide (DMSO) were purchased from Sigma-Aldrich Chemical (St. Louis, USA). 3(4,5-Dimethylthiazol-2-yl)-2,5-diphenyltetrazolium bromide (MTT), phosphate-buffered saline (PBS), Dulbecco's modified Eagle medium (DMEM), fetal bovine serum (FBS) and nonessential amino-acids were provided by Beijing BioDee Biotechnology Co.Ltd (Beijing, China). Other chemicals used were all of analytical grade.

Liana stems of ten woody herbs, i.e., E. schmidtii Craib, Porana sinensis Hemsl., Porana sinensis Hemsl. var. delavayi (Gagn. et Courch.) Rehd., Celastrus hindsii Benth., Morinda umbellata L., Illigera parviflora Dunn, Morinda parvifolia Bartl. ex DC., Piper puberulum (Benth.) Maxim., Piper kadsura (Choisy.) Ohwi, and Iodes seguini (Levl.) Rehd. ${ }^{29-32}$ marked as samples S1 through S10 in sequence were collected from herb markets of Bozhou, Anhui Province and Anguo, Hebei Province, and authenticated by Associate Prof. Dr Zhonghua Liu, Beijing Forestry University, China.

All collected herbs (S1-S10) were dried further for $24 \mathrm{~h}$ at $50{ }^{\circ} \mathrm{C}$, ground using a mill, and sieved through a no. 50-mesh to ensure homogeneous size. Each ground herb was accurately weighed $(1.5000 \mathrm{~g})$ and transferred to a $50 \mathrm{~mL}$ centrifuge tube, and $15 \mathrm{~mL}$ methanol : water $(80: 20 \mathrm{v} / \mathrm{v})$ was immediately added into the tube, which was sealed and extracted in an ultrasonic bath for $30 \mathrm{~min}$. The tube was then centrifuged at $800 \mathrm{rpm}$ for $5 \mathrm{~min}$, and the supernatant was collected. These extraction procedures were repeated twice more. The three supernatants of each herb were merged together, filtered through a $0.22 \mu \mathrm{m}$ membrane, and stored at $4{ }^{\circ} \mathrm{C}$ to obtain extract solutions for measurement of phenolics, determination of antioxidant activities, and HPLC quantification and fingerprints analyses. For further assessment of anti-inflammatory activities, extract solutions of S1-S5 were also evaporated using a rotary evaporator (Labconco, Kansas city, MO, USA) until dryness, then the dried extracts were dissolved in DMEM at different concentrations and filtered by sterile syringe filter with a $0.22 \mu \mathrm{m}$ pore size.

\subsection{Measurement of phenolics}

2.2.1. Total flavonoids. Total flavonoids of the ten herbs (S1-S10) were examined by an aluminium chloride colorimetric assay $^{33}$ with slight modifications. Briefly, $120 \mu \mathrm{L}$ appropriately diluted solution of individual samples were mixed with $8 \mu \mathrm{L}$ sodium nitrite $\left(50 \mathrm{mg} \mathrm{mL} \mathrm{m}^{-1}\right.$ ) in the designated well of a 96-well microplate, then the microplate was stood for $6 \mathrm{~min}$ before addition of $8 \mu \mathrm{L}$ aluminium chloride $\left(100 \mathrm{mg} \mathrm{mL}^{-1}\right)$ into each well. After a $5 \mathrm{~min}$ incubation at room temperature, $100 \mu \mathrm{L}$ sodium hydroxide (40 mg $\mathrm{mL}^{-1}$ ) were added to each well. Subsequently, the mixture was mixed thoroughly by pipetting up and down for 10 times. The microplate was then covered and incubated in darkness at room temperature for $30 \mathrm{~min}$, and absorbance measurement was read at $410 \mathrm{~nm}$ by using a microplate reader (Tecan infinite 200, Swiss). All determinations were performed in triplicate and results were expressed as rutin equivalents from the calibration curve of rutin standard solution 
(0-100 $\left.\mathrm{mg} \mathrm{L}^{-1}\right)$ and expressed as $\mathrm{mg}$ rutin equivalents per $100 \mathrm{~g}$ d.w. plant material (per $100 \mathrm{~g}$; hereafter, if no otherwise specified, ' $100 \mathrm{~g}$ ' means ' $100 \mathrm{~g}$ d.w. plant material' in the text.).

2.2.2. Total phenols. Total phenols in S1-S10 were evaluated using Folin-Ciocalteau's method ${ }^{34,35}$ with slight modifications. In brief, $20 \mu \mathrm{L}$ appropriately diluted solution of individual samples were mixed with $40 \mu \mathrm{L}$ Folin-Ciocalteau reagent (25\%) in corresponding well of a 96-well microplate. After $5 \mathrm{~min}$ standing at room temperature, $140 \mu \mathrm{L}$ sodium carbonate solution $(700 \mathrm{mM})$ were added to each well and the plate was shaken for $30 \mathrm{~s}$ at $500 \mathrm{rpm}$ in an orbital shaker. The microplate was then covered and incubated in darkness at $40{ }^{\circ} \mathrm{C}$ for $30 \mathrm{~min}$, followed by reading at $765 \mathrm{~nm}$ using the microplate reader. Results were expressed as gallic acid equivalents from the calibration curve of gallic acid standard solutions $\left(0-400 \mathrm{mg} \mathrm{L}^{-1}\right)$ and expressed as mg gallic acid equivalents per $100 \mathrm{~g}$. All assays were performed in triplicate.

2.2.3. Total tannins. Total tannins in S1-S10 were determined based on phosphomolybdenum tungstic acid-casein reaction described by Zhao et al. ${ }^{36}$ with slight modifications. Briefly, $25 \mu \mathrm{L}$ appropriately diluted solution of individual samples were mixed with $100 \mathrm{mg}$ casein and incubated at room temperature for $3 \mathrm{~h}$ with shaking at $200 \mathrm{rpm}$. After incubation, this mixture was filtered through a $0.45 \mu \mathrm{m}$ filter to collect the supernatant, named as the corresponding sample after CASEINprecipitating reaction. The rest steps were the same as the method for determination of total phenols. Total tannins equal the difference of total phenols between samples before and after CASEIN-Precipitating Reaction. All determinations were conducted in triplicate and results were expressed as $\mathrm{mg}$ gallic acid equivalent per $100 \mathrm{~g}$.

\subsection{Determination of antioxidant activities}

2.3.1. DPPH ${ }^{*}$ scavenging activity. $\mathrm{DPPH}^{*}$ scavenging activities of S1-S10 were determined using the method of Alañon et $a l .{ }^{37}$ with slight modifications. Briefly, $10 \mu \mathrm{L}$ standard (trolox 10-400 $\mathrm{mg} \mathrm{L}^{-1}$ ), each of S1-S10 or blank (distilled water) were added to corresponding well, followed by addition of $40 \mu \mathrm{L}$ freshly prepared DPPH solution $(1 \mathrm{mM})$ and $190 \mu \mathrm{L}$ methanol to each well. The 96-well plate was then shaken at $200 \mathrm{rpm}$ for $1 \mathrm{~min}$. After incubated for $30 \mathrm{~min}$ at room temperature in darkness, absorbance was read at $517 \mathrm{~nm}$ using the microplate reader. Radical scavenging activity (RSA) for DPPH was calculated as RSA $(\%)=\left(A_{0}-A_{\mathrm{s}}\right) / A_{0} \times 100$, where $A_{\mathrm{s}}$ is the absorbance of the sample and $A_{0}$ is that of the blank. All examinations were performed in triplicate and results were expressed as $\mathrm{mg}$ trolox equivalents per $100 \mathrm{~g}$.

2.3.2. ABTS $^{+}$scavenging activity. $\operatorname{ABTS}^{+\bullet}$ scavenging activities of S1-S10 were analyzed using the method reported by Alañón et al. ${ }^{37}$ with minor modifications. $\operatorname{ABTS}^{+\cdot}$ was generated by the reaction of a $7 \mathrm{mM}$ aqueous solution of ABTS with a $2.4 \mathrm{mM}$ aqueous solution of $\mathrm{K}_{2} \mathrm{~S}_{2} \mathrm{O}_{8}$ in equivalents. The $\mathrm{ABTS}^{+}$solution was kept in darkness at room temperature for 12-16 $\mathrm{h}$, then diluted with methanol at a ratio of $1: 48$ to an absorbance of $0.70 \pm 0.02$ at $734 \mathrm{~nm}$ to produce an $\mathrm{ABTS}^{+}$ working solution. After the working solution was prepared, $5 \mu \mathrm{L}$ standard solution (20-100 $\mathrm{mg} \mathrm{L}^{-1}$ trolox, final concentration), each of S1-S10 or blank (distilled water) was quickly added to corresponding wells in a 96-well microplate, followed by adding $200 \mu \mathrm{L}$ working solution to each well. After incubation for $5 \mathrm{~min}$ at $30{ }^{\circ} \mathrm{C}$ in darkness, absorbance was read again at $734 \mathrm{~nm}$ using the microplate reader. The RSA for ABTS was also calculated as RSA $(\%)=\left(A_{0}-A_{\mathrm{s}}\right) / A_{0} \times 100$, where $A_{\mathrm{s}}$ is the absorbance of the sample solution and $A_{0}$ is the absorbance of the blank. All examinations were performed in triplicate and results were expressed as mg trolox equivalents per $100 \mathrm{~g}$.

2.3.3. ORAC. ORAC assay was conducted according to Sun et $a l .{ }^{38}$ All reagents in the ORAC assay were prepared with and reactions were conducted in a $75 \mathrm{mM}$ phosphate buffer $(\mathrm{pH}=$ 7.4). Experiments were protected from direct light due to lightsensitivity of fluorescein. In brief, $75 \mu \mathrm{L}$ fluorescein solution $(0.2 \mu \mathrm{M})$ was added to each well of the 96-well plate, then $25 \mu \mathrm{L}$ individual trolox standard solutions (5-50 $\mu \mathrm{M}$, final concentration), each of S1-S10 or $75 \mathrm{mM}$ phosphate buffer (reagent blank) was added to the corresponding well. After shaking at $250 \mathrm{rpm}$ for $5 \mathrm{~min}$, the plate was kept in darkness and incubated in a $37^{\circ} \mathrm{C}$-prewarmed oven for $15 \mathrm{~min}$. Once the incubation was completed, $100 \mu \mathrm{L} 37^{\circ} \mathrm{C}$-prewarmed AAPH was quickly added to each well by a 12-channel multipipet. The microplate was then immediately placed in the 96-well microplate reader and fluorescence was recorded every $1.5 \mathrm{~min}$ for $75 \mathrm{~min}$ with an excitation at $530 \mathrm{~nm}$ and emission at $485 \mathrm{~nm}$. The net Area under Curve (AUC) of samples and standards were calculated by subtracting the AUC of the blank. Results were calculated by comparing the net AUC of the sample with that of the standard. All examinations were performed in triplicate and results were expressed as mg trolox equivalents per $100 \mathrm{~g}$.

\subsection{HPLC quantification and fingerprints analyses}

Accurately weighed standard scopolin, chlorogenic acid or scopoletin was dissolved into methanol : water $(80: 20 \mathrm{v} / \mathrm{v})$ to yield corresponding stock solution at $1.0 \mathrm{mg} \mathrm{mL}^{-1}$, and its standard solution was prepared by serial dilution of the stock solution to the working range of mobile phase for each standard. All standard solutions at 1.0, 0.5 and $0.25 \mathrm{mg} \mathrm{mL}^{-1}$ were stored at $4{ }^{\circ} \mathrm{C}$ in darkness, kept at room temperature for $10 \mathrm{~min}$, and filtered through a $0.22 \mu \mathrm{m}$ filter prior to HPLC analyses.

HPLC analyses were carried out with a Shimadzu HPLC system (Shimadzu, Kyoto, Japan) equipped with a SPDM20A ultraviolet detector, an Eclipse XDB-C18 column (Agilent, $250 \mathrm{~mm} \times 4.6 \mathrm{~mm}$ i.d., $5 \mu \mathrm{m}$ ), and a SIL-20AC TH autosampler controlled by an analytical software (LC Solution-Release 1.23SP1). Mobile phase was: (A) formic acid $(0.1 \%, \mathrm{v} / \mathrm{v})$ and (B) methanol $(100 \%, \mathrm{v} / \mathrm{v})$, and its gradient was: 0-10 $\mathrm{min}, 15-34 \% \mathrm{~B} ; 10-20 \mathrm{~min}, 34 \% \mathrm{~B} ; 20-$ 35 min, 34-38\% B; 35-45 min, 38-50\% B; 45-55 min, 50-70\% B; 55-75 $\mathrm{min}, 70-100 \% \mathrm{~B}$. Injection volume, column temperature,

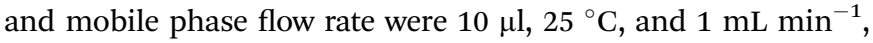
respectively, and monitor wavelength was set at $310 \mathrm{~nm}$.

\subsection{Assessment of anti-inflammatory activities}

2.5.1. Cell culture and viability assay. Murine macrophages (RAW264.7 cells) were purchased from Cell Bank of Chinese 
Academy of Medical Sciences (Beijing, China) and cultured in high-glucose DMEM supplemented with 10\% FBS, two antibiotics (penicillin, 100 units per $\mathrm{mL}$; streptomycin, $100 \mu \mathrm{g}$ $\mathrm{mL}^{-1}$; Solarbio, Beijing, China) and $0.5 \%$ non-essential amino-acids in a humidified atmosphere at $37{ }^{\circ} \mathrm{C}$ with $5 \%$ $\mathrm{CO} 2$. In brief, cultured cells were seeded in a 96-well plate at a density of $3 \times 10^{4}$ cells per well and grown for $24 \mathrm{~h}$, then the medium was removed and different concentrations of S1, S2, $\mathrm{S} 3, \mathrm{~S} 4$ or S5 were added $2 \mathrm{~h}$ before treatment with LPS at a final concentration of $1 \mu \mathrm{g} \mathrm{mL}{ }^{-1}$. After incubation for $24 \mathrm{~h}, 20 \mu \mathrm{L}$ MTT ( $5 \mathrm{mg} \mathrm{mL}^{-1}$ ) was added, and MTT was converted by the cells into visible formazan crystals after $4 \mathrm{~h}$ incubation. The formazan crystals were then dissolved in DMSO and absorbances were measured at $570 \mathrm{~nm}$ using the microplate reader. Relative cell viability was calculated and compared with untreated control.

2.5.2. NO production. NO release by the RAW264.7 cells $\left(3 \times 10^{5}\right.$ cells per well) was firstly assessed by detecting the amount of sodium nitrite in the culture medium using the Griess test. Briefly, after $2 \mathrm{~h}$ treatment with different concentrations of S1-S5, the cells were incubated for $19 \mathrm{~h}$ with LPS at a final concentration of $1 \mu \mathrm{g} \mathrm{mL}^{-1}$. Then, $50 \mu \mathrm{L}$ Griess A $(1 \%$ sulfanilamide in $\left.5 \% \mathrm{H}_{3} \mathrm{PO}_{4}\right)$ and $50 \mu \mathrm{L}$ Griess B $(0.1 \% N-1$ naphthyl-ethylenediamine- $\mathrm{HCl}$ ) were added to $100 \mu \mathrm{L}$ culture medium. Absorbance was detected at $540 \mathrm{~nm}$, and a standard curve was established using $\mathrm{NaNO}_{2}$ for calculating the sodium nitrite concentrations.

2.5.3. qRT-PCR assay. For qRT-PCR assay, RAW264.7 cells were seeded onto 6 -well plates at $1 \times 10^{6}$ cells per well and incubated for $24 \mathrm{~h}$ prior to treatments. Then, the supernatant were removed and after $2 \mathrm{~h}$ treatment with different concentrations of S1-S5, the cells were incubated for $19 \mathrm{~h}$ with LPS at a final concentration of $1 \mu \mathrm{g} \mathrm{mL}^{-1}$. Next, the cells were washed with cold PBS and total RNA was extracted with trizol reagent (Tiangen Biotech, Beijing, China). Isolated RNA (1.5 $\mu \mathrm{g})$ was converted to cDNA in a $20 \mu \mathrm{L}$ reaction volume using a TIAN Script RT Kit (Tiangen Biotech, Beijing, China) according to the manufacturer's instructions. The cDNA encoding iNOS, COX-2, interleukin-6 (IL-6) and interleukine-1 $\beta$ (IL-1 $\beta$ ) mRNAs were then quantified by qRT-PCR. Briefly, all reactions were performed in the 96-well plates with the following procedures: predenaturation at $95{ }^{\circ} \mathrm{C}$ for $2 \mathrm{~min}, 45$ cycles of denaturation at $95{ }^{\circ} \mathrm{C}$ for $10 \mathrm{~s}$, and annealing and extension at $60{ }^{\circ} \mathrm{C}$ for $32 \mathrm{~s}$. $\beta$-Actin was used as the internal reference. Sequences of specific primers were listed in Table 1 . Analyses of the data were performed by the $2^{-\Delta \Delta \mathrm{Ct}}$ method using $\beta$-actin for normalization of the samples.

\subsection{Statistical analysis}

Data were presented as mean $\pm \mathrm{SD}(n=3)$ and analyzed by IBM SPSS statistical software 20.0 (SPSS Inc., Chicago, IL) with $p<$ 0.05 as significant. Evaluation of chromatographic fingerprints were conducted by Similarity Evaluation System for Chromatographic fingerprint of Traditional Chinese Medicine (version 2004A, National Committee of Pharmacopoeia, China).

\section{Results and discussion}

\subsection{Differences in contents of total phenolics between E. schmidtii and its nine adulterants}

3.1.1. Total flavonoids. Fig. 1A shows total flavonoids of $E$. schmidtii and its nine adulterants measured by an aluminium chloride colorimetric assay. Obviously, S3 was the highest (5219.27 $\mathrm{mg}$ gallic acid per $100 \mathrm{~g}$ ), followed by S2 (4399.42), with an order from high to low of the other eight herbs being S9, S1, S4, S7, S5, S6, S8, and S10. And they all exhibited significant differences between each other except S1 and S4. Flavonoids have been reported to contribute to antioxidant activity, as they act on enzymes and pathways involved in anti-inflammatory processes. ${ }^{39}$ Awah et $a .^{40}$ determined total flavonoids of several medicinal plants distributed in Nigerian using the same method but their results in $\mathrm{mg}$ rutin equivalents were based on per $\mathrm{g}$ d.w. extract rather than plant material. Among these medicinal plants, the plant extract of Eupatorium adenophorum (6360 mg rutin equivalents per $100 \mathrm{~g} \mathrm{~d}$. w. extract), Cassia sieberiana (2040) and Canthium subcordatum (1560) used for the treatment of inflammation and arthritis exhibited similar or less total flavonoids than those in S3, S2, S9 (2370.84 mg gallic acid per $100 \mathrm{~g}$ ), and S1 (2131.58). Considering our data are on a plant material rather than extract base, there must be more herbs in our study that possessed higher total flavonoids. Leandroj et $a l^{41}$ reported total flavonoids of 19 Colombian Amazonian plants (most of them used also for treatment of inflammation) and obtained identical results expressed as $\mathrm{mg}$ catechin, rather than rutin, per $\mathrm{g}$ d.w. plant material, with the highest found in Piper putumayoense (1020.03) and the lowest in Anacardium occidentale (1.00). Since rutin and catechin shared basic structures of two benzene rings and a dihydropyran heterocycle, it is reasonable to conclude that total flavonoids of S1-S3 and S9 in the present study were much higher and quite noticeable compared with these 19 plants.

3.1.2. Total tannins. Total tannins of $\mathrm{S} 1-\mathrm{S} 10$ measured using a casein-precipitating reaction were shown Fig. 1B. It is clear that S2 exhibited outstandingly the highest content (2382.25 mg gallic acid per $100 \mathrm{~g}$ ) and was significantly higher

Table 1 qRT-PCR primer sequences

\begin{tabular}{lll}
\hline Gene & Sense primer sequences & Antisense primer sequences \\
\hline iNOS & $5^{\prime}$-AATGGCAACATCAGGTCGGCCATCACT-3' & $3^{\prime}$-GCTGTGTGTCACAGAAGTCTCGAACTC-5' $^{\prime}$ \\
IL-6 & $5^{\prime}$-GAGGATACCACTCCCAACAGACC-3' & $3^{\prime}$-AAGTGCATCATCGTTGTTCATACA-5' \\
COX-2 & $5^{\prime}$-TGAAGCCGTACACATCATTTGAA-3' & $3^{\prime}$-TGGTCTCCCCAAAGATAGCATCT-5 $^{\prime}$ \\
IL-1 $\beta$ & $5^{\prime}$-TGCAGAGTTCCCCAACTGGTACATC-3' & $3^{\prime}$-GTGCTGCCTAATGTCCCCTTGAATC-5' \\
$\beta$-Actin & $5^{\prime}$-GTGCTATGTTGCTCTAGACTTCG-3' & $3^{\prime}$-ATGCCACAGGATTCCATACC-5'
\end{tabular}



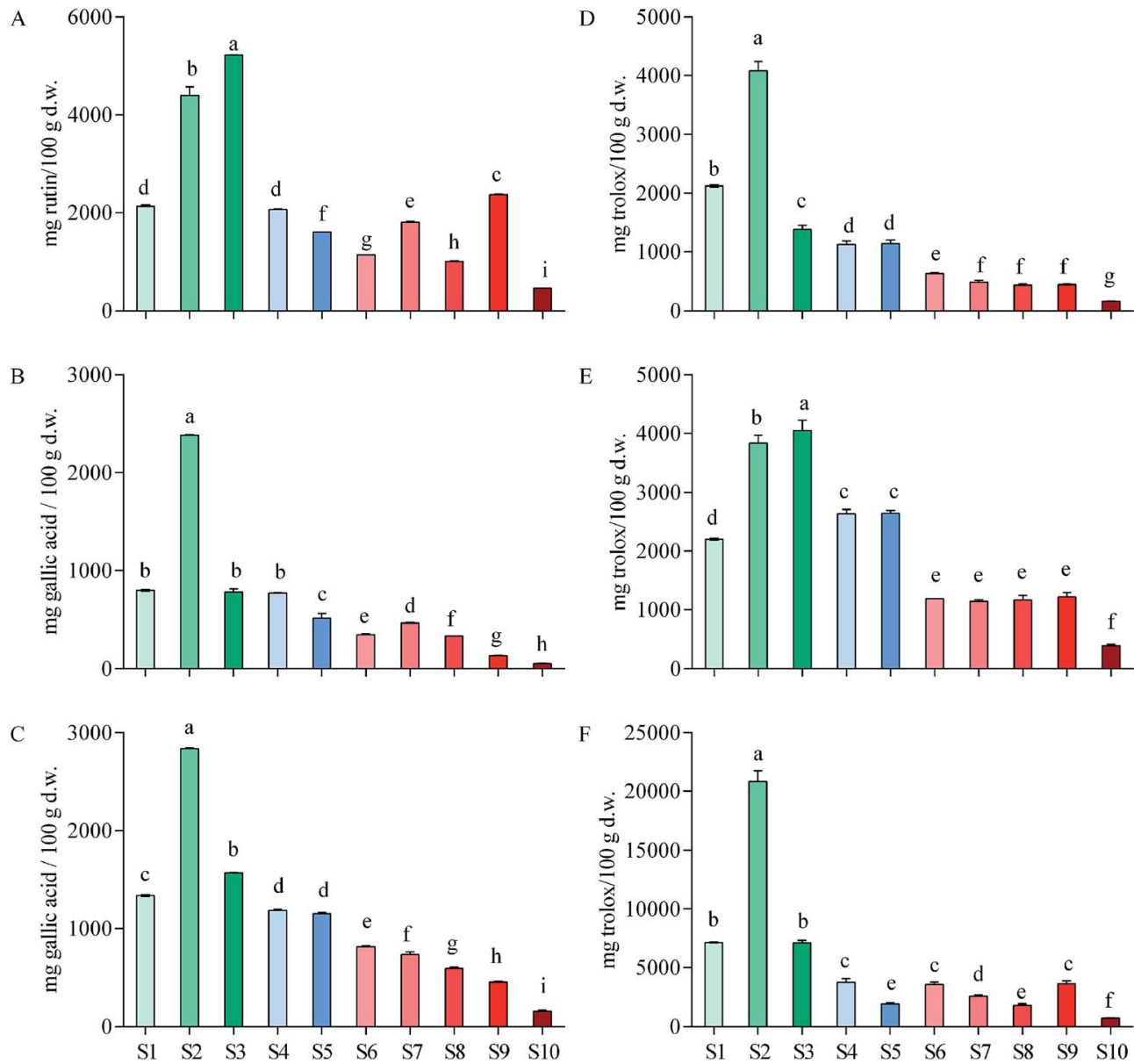

Fig. 1 Total flavonoids, tannins and phenols, and antioxidant capacities of E. schmidtii (S1) and its nine adulterants (S2-S10 as defined in the Materials and methods). Rutin was used as the standard for total flavonoids, gallic acid was that for measurements of total phenols and total tannins, and trolox was used as the standard for all the three antioxidant assays. Absorbance was determined at $410 \mathrm{~nm}$ for total flavonoids (A), $765 \mathrm{~nm}$ for total tannins (B) and total phenols (C), $517 \mathrm{~nm}$ for DPPH (D), and $734 \mathrm{~nm}$ for ABTS (E). Fluorescence for ORAC (F) was recorded with an excitation at $530 \mathrm{~nm}$ and emission at $485 \mathrm{~nm}$ every $1.5 \mathrm{~min}$ for $75 \mathrm{~min}$. Antioxidant data were calculated as the radical scavenging activity (RSA) (\%) for both DPPH and ABTS, and as the net Area under Curve (AUC) for ORAC. Results were presented as mean \pm SD of three independent experiments $(n=3)$ and expressed as mg standard per $100 \mathrm{~g} \mathrm{~d}$.w. plant material. Different letters correspond to significant differences $(p<0.05)$ by one-way analysis of variance.

than that in S1 (800.97) that was similar to those of S3 (780.29) and S4 (771.23) but with no significant differences. From S5 to $\mathrm{S} 10$, total tannins were significantly decreased in sequence from 513.22 to 51.96, with S7 (463.16) as an exception. Tannins are also good antioxidant components as they can reduce metallic ions such as $\mathrm{Fe}^{3+}$ to $\mathrm{Fe}^{2+}$ and inhibit the activity of 5-lipoxygenase in arachidonic acid metabolism that is important in inflammation physiology. ${ }^{42}$ Qasim et $a l .{ }^{43}$ analyzed total tannins of five herbs possessing high antioxidant capacity among 100 medicinal plants, and found that Salvadora persica, which was associated with wound-healing and anti-inflammatory activity, possessed the highest total tannins (1996 mg tannin acid equivalent per $100 \mathrm{~g}$ ). Since a tannin acid was consisted of as more as ten gallic acid units and only one glucose, total tannins in the above study should be comparable to ours using gallic acid as the standard. Our results showed that total tannins of S2 $(2382.25 \mathrm{mg}$ gallic acid per $100 \mathrm{~g}$ ) were dramatically higher than that of the five herbs they analyzed.
3.1.3. Total phenols. Fig. 1C shows total phenols of $E$. schmidtii and its nine adulterants measured using the FolinCiocalteu method. Clearly, all the samples (S1-S10) exhibited a wide range of total phenols with significant differences to each other except that there exists no significant difference between S4 and S5. From S2 to S10, total phenols were decreased in sequence from 2836.04 to $158.90 \mathrm{mg}$ gallic acid per $100 \mathrm{~g}$. Here we must point out that it was according to this order from the highest to the lowest were the nine adulterants of E. schmidtii defined as S2-S10 as already employed in the Materials and methods as well as the above descriptions of total flavonoids and total tannins. Anyway, S1 exhibited also relatively high total phenols (1336.48) which ranked the third among all the ten herbs. In a previous study, Li et $a l^{44}$ reported total phenols of 223 medicinal plants distributing in China and possess multiple biological activities, including antitumor, antimutagenic, anti-aging, anti-hypertensive, anti-inflammatory, antibacterial and anti-allergic properties. Among these 223 
species, total phenols of S1-S3 in the present study exceeded 161 of them with S2 and S3 exceeding 205 and 178, respectively, including such famous Chinese medicinal herbs traditionally used for anti-inflammatory and analgesic treatments as Trachelospermum jasminoides (1254.00 mg gallic acid per $100 \mathrm{~g}$ ), Taraxacum mongolicum (1105.00) and Sinomenium acutum (706.00). Leandroj et al. ${ }^{\mathbf{4 1}}$ investigated total phenols of 19 Amazonian plants traditionally utilized for treatment of symptoms associated with inflammatory processes, among which Uncaria guianensis exhibited the highest content (466.00), a value being even lower than that in S8 (591.79), the third lowest in the current study.

By calculation based on gallic acid equivalent, total tannins contributed to a considerable proportion of total phenols in the ten herbs (29.23-84.00\%), with the largest proportion being found in S2. Total tannins accounted for more than half (59.93\%) of total phenols in S1 (Fig. 1B and C). It can be concluded that tannins were one of the major components in these medicinal vines. In addition, as total flavonoids in rutin equivalent accounted for $0.5-5.2 \%$ of these vines in dry weight, and total flavonoids in $\mathrm{S} 1$ accounted for $2.1 \%$, it can be conferred that they contained also considerable flavonoids (Fig. 1A). Overall, S1, as well as S2-S4, contained considerable phenols, tannins and flavonoids comparing with other herbs that were associated with anti-inflammatory activity.

Pharmacists usually target an herb with high total phenols including tannins and flavonoids for treating different diseases. ${ }^{45}$ High total phenols indicate a high ability of the herb to dealing inflammatory diseases and are implicated in wound healing. ${ }^{46}$ Therefore, it can be concluded that total phenols in $E$. schmidtii (S1) were considerable high among the main medicinal plans used for anti-inflammatory thus itself can be confirmed as a good Chinese medicine to treat inflammation that have in fact been employed in the long-term practice by veteran doctors of Traditional Chinese Medicine. Compared with the contents in S1, total phenols, tannins and flavonoids in S2-S4 are also considerably high (Fig. 1A-C) and they should be considered as potentially effective alternatives to rather than 'adulterants' of $\mathrm{S} 1$ (i.e., E. schmidtii).

\subsection{Differences in antioxidant activities between $E$. schmidtii and its nine adulterants}

3.2.1. DPPH ${ }^{\circ}$ scavenging abilities. $\mathrm{DPPH}^{\circ}$ scavenging capacities of E. schmidtii and its nine adulterants (Fig. 1D) show that S2 exhibited notably the highest DPPH activity $(4080.46 \mathrm{mg}$ trolox per $100 \mathrm{~g}$ ) and was significantly higher than that of S1 (2122.22). From S3 to S10, DPPH activities decreased in sequence from 2836.04 to 158.90 with no statistic differences between S4 and S5 as well as among S7-S9. Furthermore, this order of $\mathrm{DPPH}^{*}$ scavenging abilities was similar to that of total phenols (Fig. 1C), indicating that total phenols contribute greatly to the scavenging ability. Chirinos et al. ${ }^{47}$ reported $\mathrm{DPPH}^{\circ}$ scavenging abilities of 27 selected andean medicinal plants, with the highest found in Alnus acuminata $(20343.57 \mathrm{mg}$ trolox per $100 \mathrm{~g}$ ) and the lowest in Amaranthus caudatus (30.03). Our S2 exceeded 15 and S1, S3, S4 and S5 exceeded 10 of their 27 plant species. Among the 10 plants, Oxalis tuberosa (210.24) was used against rheumatism and arthritis.

3.2.2. ABTS $^{+\bullet}$ scavenging abilities. As shown in Fig. 1E, S3 (4047.51 $\mathrm{mg}$ trolox per $100 \mathrm{~g}$ ) shows the strongest $\mathrm{ABTS}^{+}$ scavenging ability which is significantly higher than that of S2 (3834.63). S5 and S4 (2645.17 and 2634.08) rank the third and fourth, respectively, followed by S1 (2205.98), S9, S8, S6, S7 (1218.63-1142.18), and S10 (392.13), with no significant differences between S4 and S5 as well as among S6-S9. Comparing to $\mathrm{ABTS}^{+}{ }^{+}$scavenging abilities reported by Leandroj et al. ${ }^{\mathbf{4 1}} \mathrm{S} 1-\mathrm{S} 5$ exceeded 16 of their 19 medicinal plants investigated, and S2 and S3 exhibited even higher ABTS activities than that of their highest species, i.e., Crescentia cujete (2925 mg trolox per $100 \mathrm{~g}$ ). Similarly, $\mathrm{ABTS}^{+}{ }^{+}$scavenging abilities of S1-S5 were stronger than 158 species of the 223 medicinal plants determined by $\mathrm{Li}$ et $a .^{\mathbf{4 4}}$

Floegel et $a .^{48}$ reported antioxidant capacity of 50 most popular foods in USA by ABTS/DPPH assays, and the results showed that the DPPH data of each food were similar to the ABTS data of itself. Similar results were found in Acer truncatum leaves ${ }^{49}$ and oak cup crude extract. ${ }^{50}$ However, it was found by the present study that the ABTS values of each vine herb (Fig. 1E) were significant higher than its DPPH values (Fig. 1D). This is probably an important finding, since it raises a possibility that those compositions that were more sensitive to $\mathrm{ABTS}^{+}{ }^{+}$than to $\mathrm{DPPH}^{\bullet}$ in these herbs likely belong to alkaloids or other nitrogen-containing components that might also be responsible for the inflammatory activities.

3.2.3. Oxygen radical absorbance capacity (ORAC). ORAC assay offers several advantages over ABTS and DPPH assays. It uses peroxyl radicals ( ROO $^{\circ}$ ) that are a better model of antioxidant reactions with oxidizing lipids and reactive oxygen species (ROSs) in foods and in vivo, and it provides continuous generation of radicals on a much more realistic time scale (more or less like actual reactions in situ). ${ }^{51}$ Thus the ORAC assay is considered as a preferable method biologically relevant to in vivo anti-oxidant efficacy. Fig. $1 \mathrm{~F}$ shows oxygen radical absorbance capacities of $E$. schmidtii (S1) and its nine adulterants. Obviously, S2 exhibited the highest ORAC value $(20818.75 \mathrm{mg}$ trolox per $100 \mathrm{~g}$ ), which was almost three times of the second S1 (7136.39) and the third S3 (7094.16), followed by S4, S9, S6, S7, S5, S8, and S10 (3776.31-713.38). No significant differences observed between $\mathrm{S} 1$ and S3, S5 and S8, as well as among S4, S6 and S9. ORAC values of these ten herbs are higher than their corresponding DPPH and ABTS values as indicated by the $y$-axis values and this difference might be due to the different chemical properties of bioactive compounds and the distinct mechanisms of these three antioxidant assays.

Leandroj et $a .^{41}$ also reported ORAC values of their 19 medicinal plants used for treatment of inflammatory and rheumatic in Amazonia. By comparing our data with theirs obtained using the same AAPH radical generator, it is clear that S1-S3 showed an even higher ORAC value than all those 19 medicinal plants, with S2 was about 3-folds higher than that of their highest species. Samaradivakara et $a l .{ }^{52}$ analyzed antioxidant capacities by ORAC assay of 16 medicinal plants distributed in SriLankan. Among these medicinal plants, S2 possessed 
similar ORAC value with Caesalpinia bonducella $(20169 \mathrm{mg}$ trolox per $100 \mathrm{~g}$ extract), Elephantopus scaber (20 844) and other six medicinal plants. It must be pointed out again that our data are on a dry weight plant material rather than extract base. Considering this aspect, our data might be even higher than most of, if not all, their 16 species.

In general, it is obviously that E. schmidtii (S1) used for treating a variety of inflammations possesses a good antioxidant activity. Once again, compared with three antioxidant activities of S1, S2-S4 also exhibited a high level of antioxidant activities and thus should be taken into account as potentially effective alternatives of $E$. schmidtii. This conclusion was consistent with the previous conclusion based on measurement of phenolic contents.

\subsection{Differences in HPLC fingerprints between and quantification of the three marker compounds in E. schmidtii and its nine adulterants}

A HPLC-UV method was used for fingerprinting phytochemicals of E. schmidtii and its nine adulterants. Chromatographic and detection conditions was selected based on a previously report ${ }^{53}$ to maximize the number and relative intensity of detected signals. As shown in Fig. 2C, complex phytochemical extracts of the ten herbs were all properly resolved and a wide range of different compounds (discernible peaks) could be recognized. The chromatogram of S1 (Fig. 2B) was taken as the reference fingerprint for the nine adulterants. Similarities calculated by Similarity Evaluation System for Chromatographic Fingerprint of Traditional Chinese Medicine (Version 2004A) between the reference fingerprint and individual adulterants were listed in Table 2. Generally, the closer the values similar to the value 1 , the more similarity the two chromatograms. Obviously, the nine adulterants could be divided into two groups based on their similarities to S1, with one group consisting of S7-S10 for their similarities with $\mathrm{S} 1$ far below 0.5 and the other group thus including S2-S6. The higher similarity usually means the more similar compositions. Our results show that $\mathrm{S} 1$ possessed good composition similarities with S5, S6, S4, S2 and S3 in sequence.

It is obvious from HPLC profiles that peaks 1-3 in Fig. 2B are matched precisely to those of the three authentic standards in Fig. 2A, i.e., scopolin, chlorogenic acid, and scopoletin, respectively, which are defined as markers of the herb $E$. schmidtii by the Chinese Pharmacopoeia. And all these compounds present good anti-nociceptive and antiinflammatory activities. ${ }^{54-56}$ The right four columns of data in Table 2 show individual and total contents of the three markers in S1-S10. It can be found that S1, S3 and S2, being increased significantly in sequence from 405.36 to $475.07 \mathrm{mg}$ per $100 \mathrm{~g}$, exhibited outstandingly higher total contents of scopolin, chlorogenic acid and scopoletin than those of the other adulterants (S4-S10). Moreover, rank orders of both scopolin and scopoletin in S1-S3 was the same as that of the total contents of the three markers. For chlorogenic acid, it was contained in $E$. schmidtii (S1) and all the adulterants (S2-S10), with an order from the highest to the lowest as S5, S1-S4, S6, S9, S7, S8, and S10. The contents of scopolin, chlorogenic acid and scopoletin in E. schmidtii shows a little difference with results reported by Chen et al. ${ }^{53}$ probably due to different methods of sample preparation. From results shown in Table 2, it can be concluded that among the nine adulterants S2 and S3 could be recognized as alternatives of $\mathrm{S} 1$ as they not only contain but have high total contents of the three compounds. The total contents in S4 and S5 are also relatively higher because they possess high levels of chlorogenic acid. They might be selected as alternatives from both phenolic content and antioxidant ability bases (see Sections 3.1 and 3.2); however, they are lack of scopoletin that is recognized as one of the two active ingredients, scopolin and scopoletin, which were responsible for anti-rheumatic in $E$. schmidtii. Others (S6-S10) should be determined as quack medicines in that they contained only two of the three markers in an extremely low total amount.

Hierarchical clustering analyses (ESI Fig. S1†) show that S1 was close to S4 and S5 in phenolic components (total phenols, flavonoids and tannins, as well as the three identified phenolic compounds), antioxidant capacities (DPPH, ABTS and ORAC) and HPLC fingerprint similarities, while S2 and S3, being much higher with the above various indexes (Fig. 1 and Table 2), were clustered into another group. Correlations among the various indexes analyzed by SPSS regression were listed in ESI Table S1. $\dagger$ It is worth emphasizing that significant correlations between phenolics components and antioxidant activities indicate that total flavonoids contributed to mainly antioxidant activity of ABTS, but total tannins, to those of both DPPH and ORAC. As to the three marker compounds, scopolin possessed antioxidant capacity much higher than scopoletin and chlorogenic acid did.

In summary, all the above results indicate that S2-S5 (i.e., Porana sinensis, Porana sinensis var. delavayi, Celastrus hindsii and Morinda umbellata in sequence) could be preliminarily determined as alternatives to S1 (i.e., E. schmidtii), which required further confirmation by comparison of their antiinflammatory activities described below. The other five woody vine plants, namely, S6-S10 (i.e. Illigera parviflora, Morinda parvifolia, Piper puberulum, Piper kadsura and Iodes seguini in sequence), were identified as absolute fakes or adulterants, thus were excluded from alternatives of E. schmidtii.

\subsection{Confirmation of the alternatives to $E$. schmidtii via comparison of anti-inflammatory activities}

3.4.1. Effects of S1-S5 on viability of LPS-induced RAW264.7 cells. MTT assay was conducted first to evaluate cytotoxic effects of S1-S5 on murine macrophages (RAW264.7 cells). As we saw in Fig. 3A, RAW264.7 cells' viability maintained at $89.71 \%$ after treatment solely with LPS, which was significantly lower than those treated further with $\mathrm{S} 1$ at $25 \mu \mathrm{g} \mathrm{mL}{ }^{-1}$ and S2 and S3 at all the three concentrations but comparably the same with $\mathrm{S} 1$ and $\mathrm{S} 5$ at 50 and $100 \mu \mathrm{g} \mathrm{mL} \mathrm{m}^{-1}$. Slight but significant cytotoxicities were observed in cells further treated with $\mathrm{S} 4$ at all the three concentrations and S5 at $100 \mu \mathrm{g} \mathrm{mL}^{-1}$. The results indicate that S1-S3 at both 25,50 and $100 \mu \mathrm{g} \mathrm{mL}^{-1}$ exhibited no cytotoxicities and there existed slight cytotoxicities with $\mathrm{S} 4$ at all the three concentrations and S5 at $100 \mu \mathrm{g} \mathrm{mL} \mathrm{m}^{-1}$. 
A

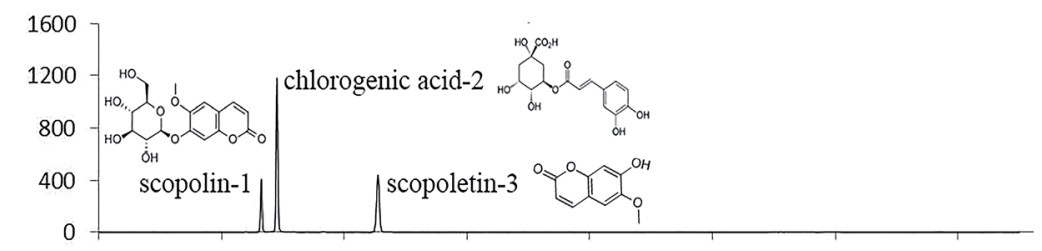

B

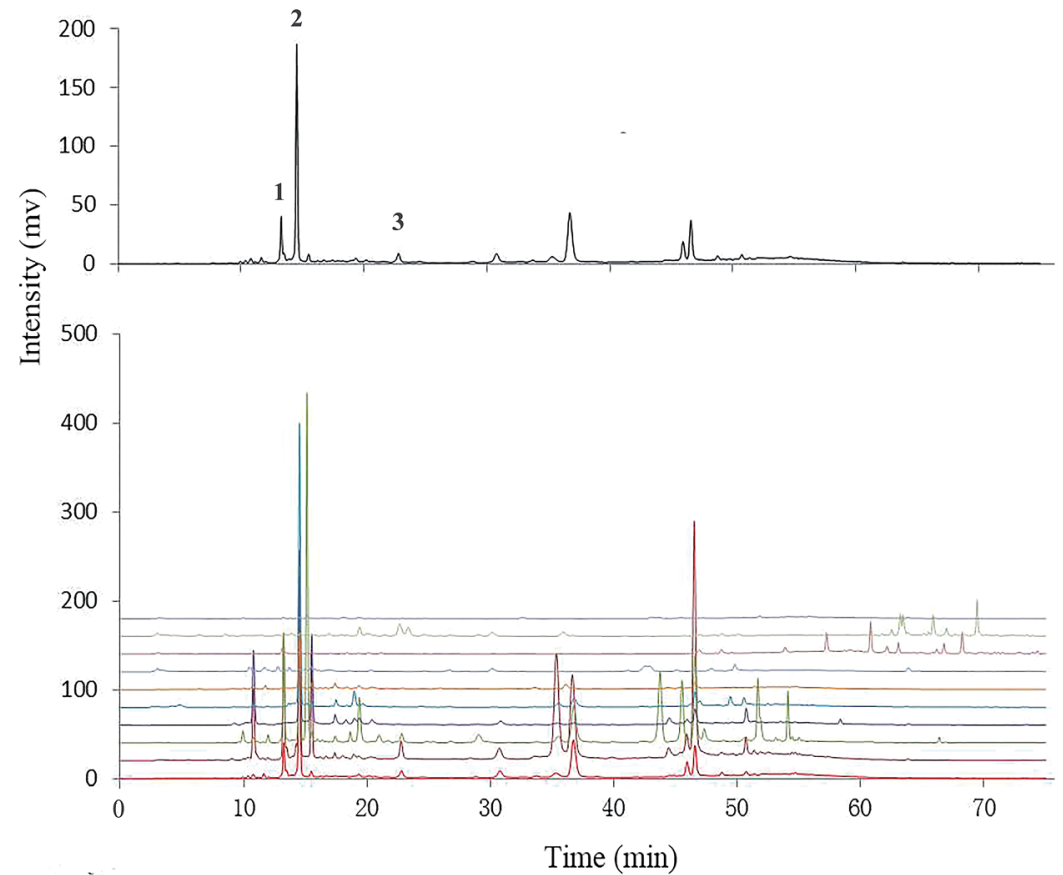

Fig. 2 HPLC profiles of the three markers (scopolin, chlorogenic acid and scopoletin) (A) and E. schmidtii (B), and chromatographic fingerprints of E. schmidtii and its nine adulterants created by the Similarity Evaluation System for Chromatographic fingerprint of Traditional Chinese Medicine (C).

3.4.2. Effects of S1-S5 on production of NO in LPS-induced RAW264.7 cells. Concentrations of NO in culture media were next determined to evaluate effects of S1-S5 on NO production by LPS-induced RAW264.7 cells (Fig. 3B). LPS significantly increased NO level compared with untreated cells. Further additions of S1-S5 to media at 25, 50 and $100 \mu \mathrm{g} \mathrm{mL} \mathrm{m}^{-1}$ all decreased NO release in a dose-dependent manner, with decreases for S2 and S3 more and S4 and S5 less dramatic than that for S1. NO as an active molecule affecting various signaling pathways may plays a regulatory role at virtually every stage of inflammation, ${ }^{57}$ previous studies have also shown that NO was associated with various neurodegenerative diseases, ${ }^{58}$ and consequently inhibition of NO has already been considered as a promising therapeutic target in treating inflammations. In the present study, we found that $\mathrm{S} 2$ and $\mathrm{S} 3$ possessed better effect on inhibition of NO release than S1 did, indicating that S2 and

Table 2 Fingerprint similarities of and scopolin, chlorogenic acid and scopoletin quantification in E. schmidtii and its nine adulterants by HPLC ${ }^{a}$

\begin{tabular}{llllll}
\hline & Similarity & S-lin* & CA & S-letin & Total \\
\hline S1 & 1 & $62.28 \pm 0.07^{\mathrm{c}}$ & $333.21 \pm 0.36^{\mathrm{b}}$ & $9.87 \pm 0.11^{\mathrm{d}}$ & $405.36 \pm 0.5^{\mathrm{c}}$ \\
S2 & 0.617 & $195.21 \pm 0.04^{\mathrm{a}}$ & $254.76 \pm 0.12^{\mathrm{c}}$ & $25.10 \pm 0.05^{\mathrm{a}}$ & $475.07 \pm 0.2^{\mathrm{a}}$ \\
S3 & 0.512 & $182.15 \pm 0.10^{\mathrm{b}}$ & $219.48 \pm 0.23^{\mathrm{d}}$ & $12.70 \pm 0.07^{\mathrm{c}}$ & $414.33 \pm 0.3^{\mathrm{b}}$ \\
S4 & 0.691 & $6.10 \pm 0.07^{\mathrm{d}}$ & $200.23 \pm 0.33^{\mathrm{e}}$ & $0^{\mathrm{g}}$ & $206.33 \pm 0.4^{\mathrm{e}}$ \\
S5 & 0.876 & $1.61 \pm 0.09^{\mathrm{f}}$ & $348.28 \pm 0.28^{\mathrm{a}}$ & $0^{\mathrm{g}}$ & $349.89 \pm 0.4^{\mathrm{d}}$ \\
S6 & 0.824 & $0^{\mathrm{g}}$ & $76.51 \pm 0.15^{\mathrm{f}}$ & $1.98 \pm 0.08^{\mathrm{e}}$ & $78.49 \pm 0.2^{\mathrm{f}}$ \\
S7 & 0.150 & $0^{\mathrm{g}}$ & $5.21 \pm 0.08^{\mathrm{g}}$ & $0.15 \pm 0.02^{\mathrm{g}}$ & $5.36 \pm 0.1^{\mathrm{h}}$ \\
S8 & 0.079 & $0^{\mathrm{g}}$ & $3.58 \pm 0.05^{\mathrm{h}}$ & $0^{\mathrm{g}}$ & $3.58 \pm 0.05^{\mathrm{i}}$ \\
S9 & 0.099 & $0^{\mathrm{g}}$ & $5.55 \pm 0.06^{\mathrm{g}}$ & $22.70 \pm 0.12^{\mathrm{b}}$ & $28.25 \pm 0.2^{\mathrm{g}}$ \\
S10 & 0.195 & $2.60 \pm 0.02^{\mathrm{e}}$ & $2.65 \pm 0.03^{\mathrm{i}}$ & $0.60 \pm 0.03^{\mathrm{f}}$ & $3.25 \pm 0.1^{\mathrm{i}}$
\end{tabular}

${ }^{a} *$ S-lin: scopolin; CA: chlorogenic acid; S-letin: scopoletin. Each sample was analyzed three times $(n=3)$; all values are mean $\pm \mathrm{SD}(\mathrm{mg} / 100 \mathrm{~g}) .{ }^{\mathrm{a}-\mathrm{i}} \mathrm{In}$ each column different letters mean significant differences between two groups $(P<0.05)$. 
A
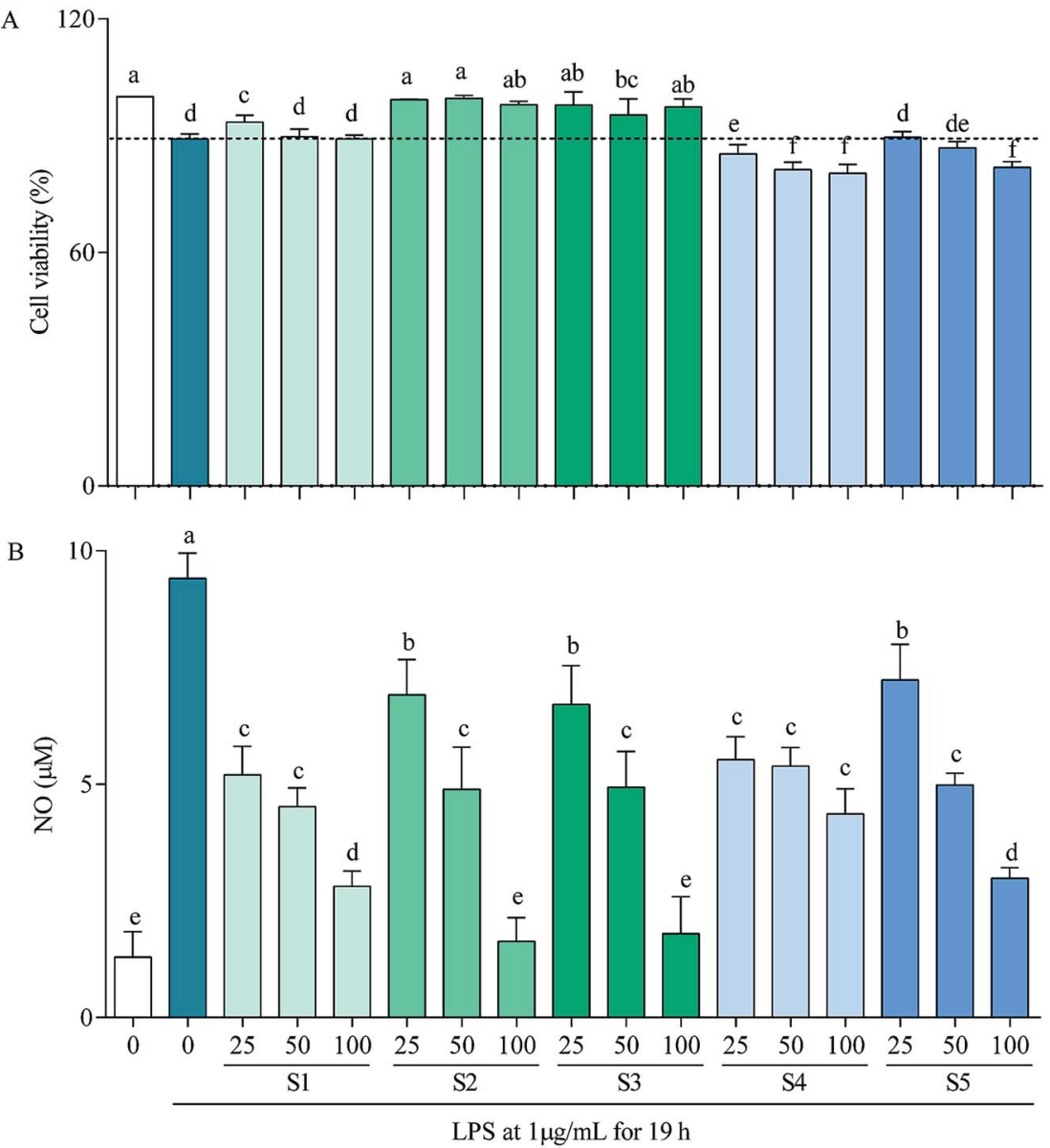

Fig. 3 Cytotoxic effects of S1-S5 (A) on and effects of S1-S5 on LPS-induced NO production (B) in RAW264.7 cells. Cells were pretreated with different concentrations of S1-S5 $\left(25,50\right.$ or $\left.100 \mu \mathrm{g} \mathrm{mL}^{-1}\right)$ or vehicle for $2 \mathrm{~h}$ and then treated with $1 \mu \mathrm{g} \mathrm{mL}{ }^{-1} \mathrm{LPS}$ for $19 \mathrm{~h}$. The results shown here are representative of 3 independent experiments and are presented as the means \pm SD.

S3 might provide a better anti-inflammatory potential in this respect.

3.4.3. Effects of S1-S5 on mRNA expressions of four inflammatory factors in LPS-induced RAW264.7 cells. As an in vitro system, RAW264.7 cells have been widely used for investigating inflammation mechanisms. To investigate whether the anti-inflammatory activities of S1-S5 was through regulation of the related gene expression, transcriptional expressions of several inflammatory factors such as iNOS, COX-2, IL-6 and IL$1 \beta$ were thus measured using qRT-PCR in LPS-induced RAW264.7 cells treated with S1-S5 at the above three concentrations (i.e., 25, 50 and $100 \mu \mathrm{g} \mathrm{mL}^{-1}$ ). As shown in Fig. 4, it was obviously that LPS significantly up-regulated mRNA expression of the four inflammatory factors. Further treatment with S1 showed significant inhibitory effects on all the mRNA expressions, with a slight promoting effect at $25 \mu \mathrm{g} \mathrm{mL} \mathrm{m}^{-1}$ and no significant inhibitory effect on those of IL-1 $\beta$ at $50 \mu \mathrm{g} \mathrm{mL} \mathrm{m}^{-1}$, respectively, as two exceptions (Fig. 4D). Adding S2 and S3 instead of $\mathrm{S} 1$ caused significantly inhibitions against mRNA expressions of iNOS, COX-2 and IL-6 (Fig. 4A-C) but promoted that of IL-1 $\beta$ (Fig. 4D) both in a dose-dependent manner. On the other hand, while S4 and S5 also significantly inhibited mRNA expressions of iNOS and COX-2 in a dose-dependent manner (Fig. 4A and B), they stimulated those of IL-6 and IL-1 $\beta$, with the former at $100 \mu \mathrm{g} \mathrm{mL}^{-1}$ of S4 and the later at $100 \mu \mathrm{g} \mathrm{mL}^{-1}$ of S5 as two exceptions (Fig. 4C and D).

In RAW264.7 cells, LPS can induce iNOS, COX-2, IL-6 and IL$1 \beta$ transcriptions, which consequently lead to overproductions of NO, PEG2, IL-6 and IL- $1 \beta,{ }^{59}$ with that of NO being demonstrated in Fig. 3B as a representative. Thereinto, high concentration of NO causes oxidative damage, promotes release of inflammatory cytokines, then results in inflammation and regulates cell growth and differentiation; ${ }^{60} \mathrm{COX}-2$ is inducible, at least partly via activation of NF- $\kappa \mathrm{B}$ by many factors such as cytokines, mitogens, growth factors and tumor promoters, and is over-expressed in inflammation and cancer; ${ }^{\mathbf{6 1}}$ IL-6 participates in regulation of vast majority of acute-phase proteins (APPs) produced by non-specific reactions triggered by inflammation; and IL-1 $\beta$ is produced during the initial stage of inflammation and is present in many types of inflammatory diseases. ${ }^{62}$ Inhibitions of these factors have been taken as a strategy to treat inflammation-related diseases. The present study reveals that the mechanism of anti-inflammatory by $E$. schmidtii (S1) was to suppress mRNA expressions of iNOS, COX- 

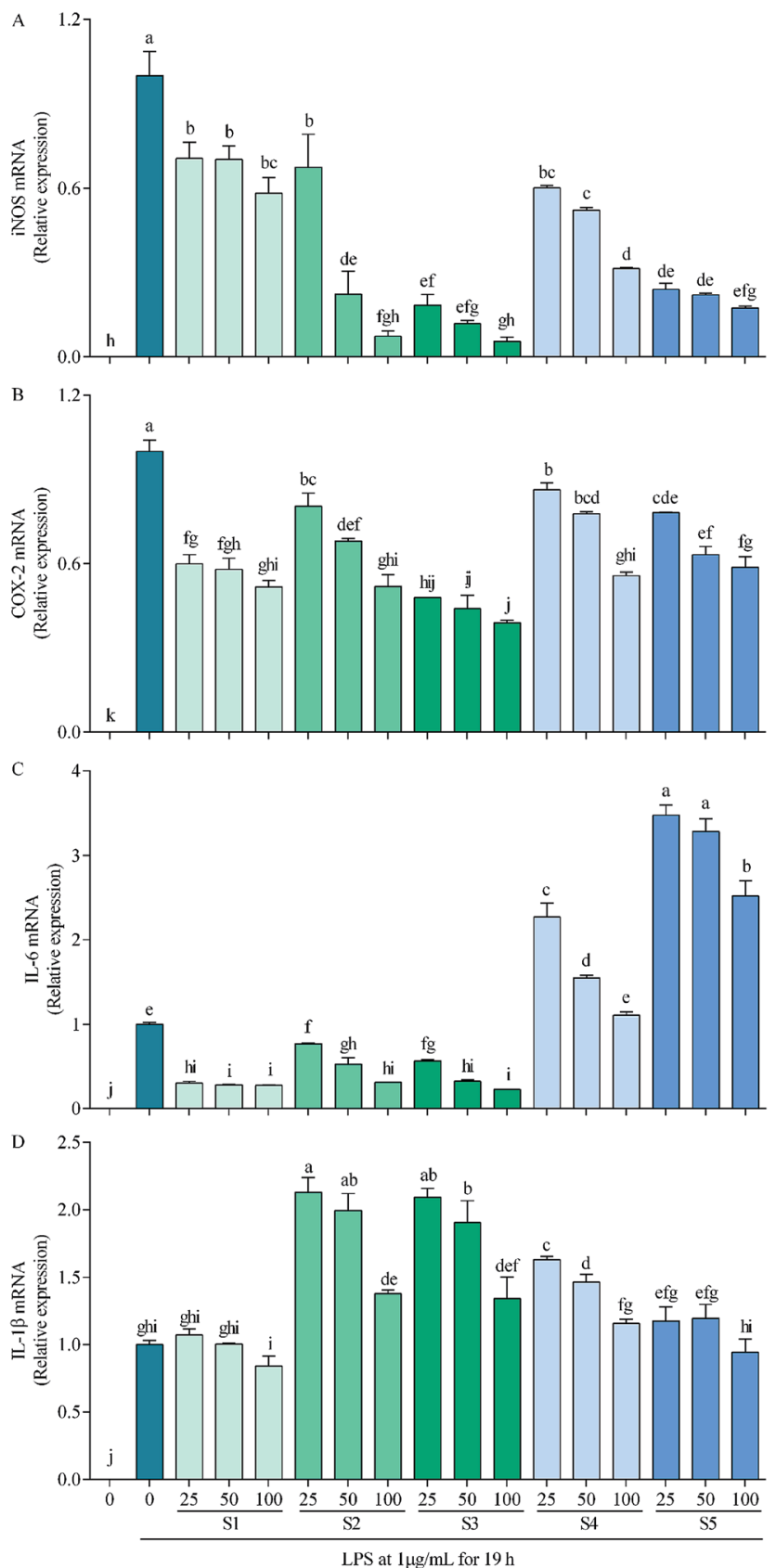

Fig. 4 Inhibitory effects of S1-S5 on gene expression of pro-inflammatory factors in LPS-induced RAW264.7 cells. Cells were incubated with $\mathrm{S} 1-\mathrm{S} 5\left(25,50\right.$ or $\left.100 \mu \mathrm{g} \mathrm{mL}^{-1}\right)$ or vehicle for $2 \mathrm{~h}$ and then treated with $1 \mu \mathrm{g} \mathrm{mL}{ }^{-1} \mathrm{LPS}$ at $37^{\circ} \mathrm{C}$. After a $19 \mathrm{~h}$ treatment with LPS, the mRNA expression levels of iNOS (A), IL-6 (B), COX-2 (C) and IL-1 $\beta$ (D) were determined by qRT-PCR and normalized to the $\beta$-actin levels. The results shown here are representative of three independent experiments and are presented as the means \pm SD.

2 and IL-6. S2 and S3 possessed the same and more effective mechanism to that of S1, and S4 and S5 suppressed mRNA expressions of only iNOS and COX-2 but not IL- 6 and IL-1 $\beta$. Therefore, it can be concluded that $\mathrm{S} 2$ and $\mathrm{S} 3$ would be the best potentially effective alternatives for $\mathrm{S} 1$ at least at the in vitro cellular level.

\section{Conclusion}

In this work, total phenols, flavonoids and tannins, and antioxidant activities of $E$. schmidtii and its nine adulterants (i.e., S2-S10) were compared thoroughly, the three marked compounds (scopolin, chlorogenic acid and scopoletin) of E. schmidtii defined by Chinese Pharmacopoeia were simultaneously quantified, and a concise and efficient HPLC fingerprints methodology for these ten liana herbs were subsequently developed. Compared with S1, there existed relatively higher phenolics in S2 and S3, with S4 and S5 containing similar or slightly lower phenolics. In in vitro antioxidant assays, S2 exhibited significant potent for scavenging free radicals than S1 did, and the antioxidant activities of S3-S5 were close to or slightly higher than that of S1. S1-S3 showed similarly large contents of scopoletin, scopolin and chlorogenic acid. Furthermore, S2-S5 also possessed better similarities with S1 than S6-S10 did. Based on the above results, anti-inflammatory activities and mechanisms of E. schmidtii (S1) and its four alternatives (i.e., S2-S5) were then explored. It is clear that S2 and S3 exhibited higher potenial in anti-inflammatory activities and similar but even more effective anti-inflammatory mechanism to that of S1. Overall, it is concluded that S2 and S3 could be two of the best potentially effective alternatives among the four alternatives of E. schmidtii, and S4 and S5 might also be considered as alternatives of E. schmidtii for they contained similar fundamental compounds and equally impressive antiinflammatory potential concerning the two inflammatory factors iNOS and COX-2. However, further animal studies and more detailed clinical research are needed to provide greater support for their use as alternatives.

\section{Conflicts of interest}

There are no conflicts of interest to declare.

\section{Acknowledgements}

This research was supported by the China Special Fund for Forestry Research in the Public Interest (Grant No. 201504606)

\section{References}

1 L. H. Wu, E. Y. Zhu, Z. J. Zhang and Z. T. Wang, Chin. Tradit. Herb. Drugs, 2005, 36, 1398-1400.

2 V. Breinholt, Desirable versus harmful levels of intake of flavonoids and phenolic acids, in Natural antioxidants and anticarcinogens in nutrition, health and disease, ed. J. Kumpulainen and J. E. Salonen, The Royal Society of Chemistry, Cambridge, 1999, pp. 93-105.

3 G. G. Duthie, S. J. Duthie and J. A. M. Kyle, Nutr. Res. Rev., 2000, 13, 79-106.

4 F. Shahidi and M. Naczk, Food phenolics: sources, chemistry, effects, applications, Technomic Publishing Co. Inc., USA, 1995.

5 F. Shahidi and M. Naczk, Phenolics in Food and Nutraceuticals, 2004, vol. 13, pp. 12-15. 
6 Y. Yi, J. Sun, J. Xie, T. Min, L. M. Wang and H. X. Wang, Molecules, 2016, 21, 863.

7 W. Song, R. L. Jin and J. H. Liu, China J. Chin. Mater. Med., 1997, 22, 359-360.

8 T. Morikawa, F. Xu, H. Matsuda and M. Yoshikawa, Chem. Pharm. Bull., 2006, 54, 1530-1534.

9 J. Liu, Z. M. Feng, J. F. Xu, Y. H. Wang and P. C. Zhang, Phytochemistry, 2007, 68, 1775-1780.

10 B. N. Ames, Science, 1983, 221, 1256-1264.

11 Y. Aniya, C. Miyagi, A. Nakandakari, S. Kamiya, N. Imaizumi and T. Ichiba, Phytomedicine, 2002, 9, 239-244.

12 L. Leong and G. Shui, Food Chem., 2002, 76, 69-75.

13 Y. Lim, T. Lim and J. Tee, Food Chem., 2007, 103, 1003-1008.

14 S. Lopes, A. Jurisicova, J. G. Sun and R. F. Casper, Hum. Reprod., 1998, 13, 896-900.

15 I. L. C. Chapple, J. Clin. Periodontol., 1997, 24, 287-296.

16 H. Y. Hsu, J. Y. Chen and J. J. Yang, Am. J. Chin. Med., 1999, 27, 117-122.

17 C. Grajeda-Iglesias, E. Salas and N. Barouh, Food Chem., 2016, 194, 749-757.

18 J. A. John and F. Shahidi, J. Funct. Foods, 2010, 2, 196-209.

19 J. Mazina, M. Vaher, M. Kuhtinskaja, L. Poryvkina and M. Kaljurand, Talanta, 2015, 139, 233-246.

20 L. Z. Yi, D. L. Yuan, Y. Z. Liang, P. S. Xie and Y. Zhao, Anal. Chim. Acta, 2007, 588, 207-215.

21 Y. Chen, S. B. Zhu, M. Y. Xie, S. P. Nie, W. Liu, C. Li, X. F. Gong and Y. X. Wang, Anal. Chim. Acta, 2008, 623, 146-156.

22 D. Xin, K. C. C. Kelvin, W. L. Hei and W. H. Carmen, J. Chromatogr. A, 2003, 1018, 85-95.

23 S. Tianniam, T. Bamba and E. Fukusaki, J. Sep. Sci., 2009, 32, 2233-2244.

24 S. P. Young, S. R. Kapoor and M. R. Viant, Arthritis Rheumatol., 2014, 65, 2015-2023.

25 M. Haemmerle, Diabetes, 2013, 7, 2509-2529.

26 T. Wyss Coray and J. Rogers, Inflammation in Alzheimer disease-a brief review of the basic science and clinical literature, Cold Spring Harbor Perspect. Med., 2012, 2, a006346.

27 M. Locatelli, J. Neuroimmunol., 2013, 1, 99-106.

28 J. S. Shin, Y. M. Park, J. H. Choi, H. J. Park, M. C. Shin, Y. S. Lee and K. T. Lee, Int. Immunopharmacol., 2010, 10, 943-950.

29 J. F. Wei and G. Xi, J. Tradit. Chin. Med., 1986, 9, 40-41.

30 Z. W. Xie, Collection of National Chinese Traditional Herbal Medicine, People's Medical Publishing House, Beijing, 1996.

31 C. M. Zhang, Y. J. Zhang and W. Song, Primary J. Chin. Mater Med., 2000, 14, 25.

32 J. N. Tan and Z. X. Gao, Journal of Guangxi Academy of Sciences, 2008, 24, 49-52.

33 U. Xie, L. Huang, C. Zhang and Y. Zhang, J. Funct. Foods, 2015, 16, 460-471.

34 F. V. Dulf, D. C. Vodnar, E. H. Dulf and M. I. Tosa, J. Agric. Food Chem., 2015, 63, 3489-3500.

35 V. L. Singleton, R. Orthofer and R. M. Lamuela Raventos, Methods Enzymol., 1999, 299, 152-178.
36 S. Zhao, J. Y. Liu, S. Y. Chen, L. L. Shi, Y. J. Liu and C. Ma, Molecules, 2011, 16, 8590-8600.

37 M. E. Alañón, L. Castro Vázquez, M. C. Díaz Maroto, M. H. Gordon and M. S. Pérez Coello, Food Chem., 2011, 128, 997-1002.

38 L. Sun, C. K. Isaak, Y. Zhou, J. C. Petkau, K. O and Y. L. Liu, Life Sci., 2012, 91, 151-158.

39 T. A. S. Araújo, N. L. Alencar, E. L. C. De Amorim and U. P. De Albuquerque, J. Ethnopharmacol., 2008, 120, 72-80.

40 F. M. Awah, P. N. Uzoegwu, P. Ifeonu, J. O. Oyugi, J. Rutherford, X. J. Yao, F. Fehrmann, K. R. Fowke and M. O. Eze, Food Chem., 2012, 131, 1279-1286.

41 L. Leandroj, B. Fadil, R. M. Begoña and R. S. José, Food Chem., 2010, 119, 1566-1570.

42 T. Okuda, Phytochemistry, 2005, 66, 2012-2031.

43 M. Qasim, Z. Abideen and M. Y. Adnan, S. Afr. J. Bot., 2016, 110, 240-250.

44 S. Li, S. K. Li, R. Y. Gan, F. L. Song, L. Kuang and H. B. Li, Ind. Crops Prod., 2013, 51, 289-298.

45 S. Petti and C. Scully, J. Dent., 2009, 37, 413-423.

46 N. Akhtara, Ihsan-ul-Haq and B. Mirza, Arabian J. Chem., 2015, 4, DOI: 10.1016/j.arabjc.2015.01.013.

47 R. Chirinos, R. Pedreschi and H. Rogez, Ind. Crops Prod., 2013, 47, 145-152.

48 A. Floegel, D. O. Kim and S. J. Chung, J. Food Compos. Anal., 2011, 24, 1043-1048.

49 L. Yang, P. Yin and K. Li, Arabian J. Chem., 2017, DOI: 10.1016/j.arabjc.2017.01.009.

50 P. Yin, L. Yang and K. Li, Arabian J. Chem., 2016, DOI: 10.1016/j.arabjc.2016.09.018.

51 K. M. Schaich, X. Tian and J. Xie, J. Funct. Foods, 2015, 14, 111-125.

52 S. P. Samaradivakara, R. Samarasekera and S. M. Handunnetti, Ind. Crops Prod., 2016, 83, 227-234.

53 Z. Chen, L. Liao, Z. Zhang, L. Wu and Z. T. Wang, J. Ethnopharmacol., 2013, 150, 501-506.

54 H. J. Kim, S. I. Jang, Y. J. Kim, H. T. Chung, Y. J. Yun, T. H. Kang, O. S. Jeong and Y. C. Kim, Fitoterapia, 2004, 75, 261-266.

55 M. D. Dos Santos, M. C. Almeida, N. P. Lopes and G. E. P. Souza, Biol. Pharm. Bull., 2006, 29, 2236-2240.

56 R. Pan, Y. Dai, X. Gao and Y. Xia, Int. Immunopharmacol., 2009, 9, 859-869.

57 G. Nagy, J. M. Clark, E. I. Buzas, C. L. Gorman and A. P. Cope, Immunol. Lett., 2007, 111, 1-5.

58 J. E. Yuste, E. Tarragon, C. M. Campuzano and F. Ros-Bernal, Front Cell Neurosci., 2015, 9, 322.

59 M. Fujihara, M. Muroi, K. Tanamoto, T. Suzuki, H. Azuma and H. Ikeda, Pharmacol. Ther., 2003, 100, 171.

60 D. J. Stuehr and M. A. Marletta, J. Immunol., 1987, 139, 518.

61 H. Ohshima, H. Tazawa, B. S. Sylla and T. Sawa, Mutat. Res., Fundam. Mol. Mech. Mutagen., 2005, 591(1), 110-122.

62 M. Mihara, M. Hashizume and H. Yoshida, Clin. Sci., 2012, 122, 143. 